\title{
Comparative analysis of sucrose phosphate synthase (SPS) gene family between Saccharum officinarum and Saccharum spontaneum
}

Panpan $\mathrm{Ma}^{1+}$, Xingtan Zhang ${ }^{1+}$, Lanping Chen ${ }^{1}$, Qian Zhao ${ }^{2}$, Qing Zhang ${ }^{1}$, Xiuting Hua ${ }^{1}$, Zhengchao Wang ${ }^{3}$, Haibao Tang ${ }^{1}$, Qingyi $\mathrm{Yu}^{1,4}$, Muqing Zhang ${ }^{5}$, Ray Ming ${ }^{6}$ and Jisen Zhang ${ }^{1,5^{*}}$ (I)

\begin{abstract}
Background: Sucrose phosphate synthase (SPS) genes play vital roles in sucrose production across various plant species. Modern sugarcane cultivar is derived from the hybridization between the high sugar content species Saccharum officinarum and the high stress tolerance species Saccharum spontaneum, generating one of the most complex genomes among all crops. The genomics of sugarcane SPS remains under-studied despite its profound impact on sugar yield.

Results: In the present study, 8 and 6 gene sequences for SPS were identified from the BAC libraries of S. officinarum and S. spontaneum, respectively. Phylogenetic analysis showed that SPSD was newly evolved in the lineage of Poaceae species with recently duplicated genes emerging from the SPSA clade. Molecular evolution analysis based on Ka/Ks ratios suggested that polyploidy reduced the selection pressure of SPS genes in Saccharum species. To explore the potential gene functions, the SPS expression patterns were analyzed based on RNA-seq and proteome dataset, and the sugar content was detected using metabolomics analysis. All the SPS members presented the trend of increasing expression in the sink-source transition along the developmental gradient of leaves, suggesting that the SPSs are involved in the photosynthesis in both Saccharum species as their function in dicots. Moreover, SPSs showed the higher expression in S. spontaneum and presented expressional preference between stem (SPSA) and leaf (SPSB) tissue, speculating they might be involved in the differentia of carbohydrate metabolism in these two Saccharum species, which required further verification from experiments.

(Continued on next page)
\end{abstract}

\footnotetext{
*Correspondence: zjisen@126.com

${ }^{\dagger}$ Panpan Ma and Xingtan Zhang contributed equally to this work.

${ }^{1}$ Center for Genomics and Biotechnology, Haixia Institute of Science and

Technology, Fujian Provincial Key Laboratory of Haixia Applied Plant Systems

Biology, College of Crop Science, Fujian Agriculture and Forestry University,

Fuzhou 350002, China

${ }^{5}$ Guangxi Key Lab of Sugarcane Biology, Guangxi University, Nanning,

Guangxi, China

Full list of author information is available at the end of the article
}

(c) The Author(s). 2020 Open Access This article is licensed under a Creative Commons Attribution 4.0 International License, which permits use, sharing, adaptation, distribution and reproduction in any medium or format, as long as you give appropriate credit to the original author(s) and the source, provide a link to the Creative Commons licence, and indicate if changes were made. The images or other third party material in this article are included in the article's Creative Commons licence, unless indicated otherwise in a credit line to the material. If material is not included in the article's Creative Commons licence and your intended use is not permitted by statutory regulation or exceeds the permitted use, you will need to obtain permission directly from the copyright holder. To view a copy of this licence, visit http://creativecommons.org/licenses/by/4.0/ The Creative Commons Public Domain Dedication waiver (http://creativecommons.org/publicdomain/zero/1.0/) applies to the data made available in this article, unless otherwise stated in a credit line to the data. 


\begin{abstract}
(Continued from previous page)
Conclusions: SPSA and SPSB genes presented relatively high expression and differential expression patterns between the two Saccharum species, indicating these two SPSs are important in the formation of regulatory networks and sucrose traits in the two Saccharum species. SPSB was suggested to be a major contributor to the sugar accumulation because it presented the highest expressional level and its expression positively correlated with sugar content. The recently duplicated SPSD2 presented divergent expression levels between the two Saccharum species and the relative protein content levels were highest in stem, supporting the neofunctionalization of the SPSD subfamily in Saccharum.
\end{abstract}

Keywords: Sugarcane, S. officinarum, S. spontaneum, Sucrose phosphate synthase (SPS), Polyploidy, BAC libraries, Transcriptome, Metabolites

\section{Background}

Sucrose is produced in plant leaves following photosynthesis along with other carbohydrates. The key organic compound constitutes the most abundant form of soluble storage carbohydrate, which can be utilized directly by glycolysis or transported from photosynthetic tissues to non-photosynthetic tissues via the phloem [1]. Sucrose therefore serves as a source of fixed carbon that can be distributed systemically throughout the plant, providing fundamental resources for direct energy production or biosynthesis of long chains of biopolymers such as starch [2] and cellulose [3].

Sucrose is synthesized in the cytosol, starting with the export of dihydroxyacetone phosphate and glyceraldehyde phosphate from the chloroplast. The following processes are catalyzed by a series of enzymes [4], in which sucrose phosphate synthase (SPS) is one of the most important ones. SPS catalyzes the conversion of Fructose-6-Phosphate (F-6-P) and UDP-Glucose (UDP-G) to Sucrose-6-Phosphate (S-6-P), providing the substrates for sucrose phosphate phosphatase (SPP). In the final step, sucrose is generated through the removal of the phosphate group. In addition to the wellrecognized role of SPS in sucrose biosynthesis in source leaves, it is becoming clear that SPS also plays an important and key role in heterotrophic cells engaging in the net sucrose degradation [5]. For example, significant turnover of the endogenous sucrose pool was observed in germinating Ricinus cotyledons [6]. This turnover of sucrose is thought to be involved in a futile cycle of simultaneous synthesis and cleavage, resulting from changes in the activation rate of SPS phosphorylation [7]. Therefore, SPS plays a crucial role in carbohydrate metabolism by regulating the partitioning of carbon between starch production and carbohydrate (sucrose) accumulation in many physiological and developmental processes.

The role of SPS was first demonstrated in wheat germ extracted by Leloir and Cardini [8] and some plants had multiple SPS genes and expression of these copies varies with developmental stages, tissue types and environmental signals [9-12], suggesting that SPS genes played divergent roles under different conditions. Recent studies showed that most SPS genes were clustered into three distinct families (A, B and C) and these genes appear to have different evolutionary histories in dicots (A family) and monocots (B family) [4]. Even though one of the SPS isoforms from sugarcane and its closely related partial sequence from barley were grouped in a family, they were somewhat more divergent than the remaining dicot SPSs that have been characterized [4]. SPS transformation experiments indicated that SPS was a major determinant inpartitioning fixed carbon from photosynthesis in the leaf and in the whole plant [13, 14]. Recently, Mark simultaneously increased SPS and glutamine synthetase (GS) activities in transgenic tobacco and found that sucrose was the major determinant of growth and development [15].

Sugarcane is the most important sugar crop in the world since it accounts for $80 \%$ worldwide sugar yield [16]. Previous SPS studies in sugarcane showed that the SPS activity and transcript expression showed higher in mature internodes than in immature internodes for all studied cultivars [17]. Meanwhile, compared to the low sugar species of sugarcane, the high sugar species showed increased transcript expressions and enzyme activities of SPS at all developmental stages [17]. In addition, expression of SPS decreased significantly in the late maturing sugarcane variety $\mathrm{BO} 91$, compared to the early maturing sugarcane variety CoJ64 [18]. The SPS members were predicted based on public EST databases $[19,20]$, and DNA fragments of amplified products from Q165 and IJ76-514 cultivars have been characterized to allow the identification all possible alleles $[19,20]$. Recent research showed that the Nterminal region of sugarcane SPS played an important role in allosteric regulation [21]. Despite the profound and well-documented role of SPS in sugarcane, the genomic sequences and biological functions for SPS members have not been identified in sugarcane due to their complicated genomes. S. officinarum and S. spontaneum are two of the most important Saccharum species not only because they are the major contributors to the genomes of modern sugarcane varieties, but they are also quite divergent with respect to sugar production [22]. In this study, to comprehensively characterize the SPS family at the molecular and evolutionary level as well as the possible functions of the 
SPS family in the two main Saccharum species, we analyzed the SPS gene family in S. officinarum and S. spontaneum and illustrated their evolutionary history, the structural and expressional differences as well possible regulatory factors through the utilization of the combinatorial analysis of transcriptome, metabolome and proteome data.

\section{Results}

Identification of SPS gene family in S. officinarum and S. spontaneum

LA Purple (S. officinarum, $2 \mathrm{n}=80$ ) and AP85-441 (the haploid clone of SES208, $2 \mathrm{n}=4 \mathrm{x}=32$ ) derived from the anther culture of SES208 (S. spontaneum, 2n =64) [23] representing two major Saccharum species were used for the construction of the BAC library. Eight and six SPS-containing BACs were isolated from S. officinarum and $S$. spontaneum, respectively (Table 1 ), with an average length of $68.6 \mathrm{~kb}$, and maximum length of $127.2 \mathrm{~kb}$ (BAC id: SES23E05). TE annotation suggested that Long Terminal Repeats (LTRs) were the major repetitive sequences in most of isolated BACs (Table 1). The putative genes including 14 sugarcane SPS sequences were annotated from the selected BACs (Additional file 1). Among the 14 SPS genes, 11 contained complete ORFs (open reading frames), with the length of coding sequences ranging from $1404 \mathrm{bp}$ to $3321 \mathrm{bp}$. For further validation, these putative SPS genes were blasted against Sorghum SPS genes and they showed high similarity, with identities ranging from 91 to $100 \%$ at the amino acid level (Table 2). In this study, we refer to the sugarcane SPS genes using SPSA to SPSD according to the sequence similarity with Sorghum SbSPSs with a prefix 'So' for S. officinarum and 'Ss' for S. spontaneum. We also identified SPS genes from the recently published Saccharum spontanenum genome [24]. Five genes without alleles were found with a similarity above $91 \%$ compared to $6 \mathrm{BAC}$ sequences (Additional file 2). There were three genes of SPSD2 (Sspon.004A0021251, Sspon.004 A0021261 and Sspon.004A0021270) in the S. spontaneum genome. To identify the duplication of three SPSD2 genes, a MCScanX program was used to the analysis referring to the research of Wang et al. [25]. The results indicated that Sspon.004A0021251 may be the primary gene produced from the whole genome duplications (WGDs), and Sspon.004A0021261 and Sspon.004A0021270 were two genes from the tandem duplication. Furthermore, to strengthen the reliability of the sequences, Sspon.007C0001731, Sspon.004A0021270 and Sspon.004A0021251 were re-annotated (Additional file 3).

\section{Homologs and allelic haplotype analysis of SPS}

To identify SPS homologs and alleles in the selected BACs, analysis of conserved synteny was performed (Additional file 4). We observed five highly similar synteny blocks among $S$. officinarum, S. spontaneum and Sorghum bicolor, indicating that the two Saccharum species contained 5 SPS gene family members. Comparison within each synteny block across the three species showed high sequence identity at DNA level and conserved gene order (Additional file 4). For instance, three SPSD1-containing BAC contigs (LA110E11, SES32E01 and SES69 K24) were identified in Saccharum, two of which were allelic haplotypes from $S$. spontaneum and one from S. officinarum. Meanwhile, the orthologous region in S. bicolor was also displayed under the three

Table 1 The results of the repeat sequence annotation for BACs containing SPS

\begin{tabular}{|c|c|c|c|c|c|c|c|c|}
\hline \multirow[t]{2}{*}{ Specie } & \multirow[t]{2}{*}{ BAC ID } & \multirow[t]{2}{*}{ Probe } & \multicolumn{3}{|c|}{ Transposable elements (\%) } & \multicolumn{3}{|c|}{ Tandem repeat sequence (\%) } \\
\hline & & & LTR & Non-LTR & Transposons & SSR & Satellite & Low complexity \\
\hline \multirow[t]{8}{*}{ S. officinarum (LA Purple) } & 84F06 & SPSA & 30.64 & 2.62 & 0.45 & 1.41 & 0.00 & 0.00 \\
\hline & 34B02 & SPSB & 15.55 & 1.74 & 3.71 & 1.24 & 0.00 & 0.17 \\
\hline & 154P24 & $S P S B$ & 19.59 & 2.13 & 1.61 & 1.25 & 0.00 & 0.13 \\
\hline & 33С13 & SPSC & 15.83 & 0.10 & 0.94 & 1.62 & 0.00 & 0.11 \\
\hline & 10401 & SPSC & 12.28 & 0.00 & 7.94 & 2.21 & 0.00 & 0.00 \\
\hline & $75 F 14$ & SPSC & 3.99 & 0.00 & 0.42 & 1.80 & 0.00 & 0.29 \\
\hline & $110 E 1$ & SPSD1 & 3.71 & 0.47 & 6.07 & 1.11 & 0.00 & 0.31 \\
\hline & $79 G 22$ & SPSD2 & 0.00 & 8.09 & 0.00 & 1.44 & 0.00 & 0.24 \\
\hline \multirow[t]{6}{*}{ S. spontaneum (SES-208) } & 23E05 & SPSA & 23.83 & 2.61 & 0.46 & 1.58 & 0.00 & 0.08 \\
\hline & $84 \mathrm{H} 16$ & $S P S B$ & 3.70 & 1.79 & 6.25 & 1.01 & 0.05 & 0.09 \\
\hline & 41F02 & SPSC & 7.75 & 0.00 & 3.44 & 1.87 & 0.00 & 0.00 \\
\hline & 32E01 & SPSD1 & 11.40 & 2.54 & 1.46 & 1.48 & 0.00 & 0.37 \\
\hline & $69 K 24$ & SPSD2 & 25.54 & 0.00 & 1.93 & 0.91 & 0.00 & 0.34 \\
\hline & 39L16 & SPSD2 & 4.42 & 1.63 & 2.66 & 1.52 & 0.00 & 0.09 \\
\hline
\end{tabular}


Table 2 Sequence similarity of SPS gene fragments between Saccharum and Sorghum

\begin{tabular}{|c|c|c|c|c|c|c|c|c|c|c|}
\hline \multicolumn{5}{|l|}{ Sorghum } & \multicolumn{5}{|c|}{ Saccharum } & \multirow[b]{2}{*}{$\begin{array}{l}\text { Identity* } \\
(\%)\end{array}$} \\
\hline Gene name & $\begin{array}{l}\text { Chromosome } \\
\text { position }\end{array}$ & $\begin{array}{l}\text { Gene Length } \\
\text { (bp) }\end{array}$ & $\begin{array}{l}\text { cDNA Length } \\
\text { (bp) }\end{array}$ & Exon & Gene nam & & $\begin{array}{l}\text { Gene Length } \\
\text { (bp) }\end{array}$ & $\begin{array}{l}\text { Protein } \\
\text { Length (aa) }\end{array}$ & Exon & \\
\hline \multirow[t]{2}{*}{$\begin{array}{l}\text { SbSPSA } \\
\text { (Sb09g028570) }\end{array}$} & Chr.9 & 12,456 & 3183 & 12 & $\begin{array}{l}\text { SOSPSA } \\
\text { SSSPSA }\end{array}$ & $\begin{array}{l}\text { S. } \\
\text { officinarum }\end{array}$ & 4658 & 468 & 9 & 99 \\
\hline & & & & & & $\begin{array}{l}\text { S. } \\
\text { spontaneum }\end{array}$ & 11,420 & 944 & 11 & 94 \\
\hline \multirow[t]{2}{*}{$\begin{array}{l}\text { SbSPSB } \\
\text { (Sb03g043900) }\end{array}$} & Chr.3 & 5575 & 3246 & 12 & $\begin{array}{l}\text { SOSPSB } \\
\text { SSSPSB }\end{array}$ & $\begin{array}{l}\text { S. } \\
\text { officinarum }\end{array}$ & 5849 & 1075 & 12 & 97 \\
\hline & & & & & & $\begin{array}{l}\text { S. } \\
\text { spontaneum }\end{array}$ & 5434 & 1107 & 12 & 91 \\
\hline \multirow[t]{2}{*}{$\begin{array}{l}\text { SbSPSC } \\
\text { (Sb05g007310) }\end{array}$} & Chr.5 & 5706 & 3216 & 9 & $\begin{array}{l}\text { SOSPSC } \\
\text { SSSPSC }\end{array}$ & $\begin{array}{l}\text { S. } \\
\text { officinarum }\end{array}$ & 6384 & 1062 & 9 & 91 \\
\hline & & & & & & $\begin{array}{l}\text { S. } \\
\text { spontaneum }\end{array}$ & 5452 & 1060 & 9 & 91 \\
\hline \multirow[t]{2}{*}{$\begin{array}{l}\text { SbSPSD1 } \\
\text { (Sb10g025240) }\end{array}$} & Chr.10 & 9887 & 3030 & 14 & $\begin{array}{l}\text { SOSPSD1 } \\
\text { SSSPSD1 }\end{array}$ & $\begin{array}{l}\text { S. } \\
\text { officinarum }\end{array}$ & 10,881 & 982 & 13 & 100 \\
\hline & & & & & & $\begin{array}{l}\text { S. } \\
\text { spontaneum }\end{array}$ & 9532 & 567 & 12 & 99 \\
\hline \multirow{2}{*}{$\begin{array}{l}\text { SbSPSD2 } \\
\text { (Sb04g005720) }\end{array}$} & Chr.4 & 6689 & 2880 & 13 & SOSPSD2 & S.officinarum & 6989 & 931 & 13 & 98 \\
\hline & & & & & SSSPSDL & $\begin{array}{l}\text { S. } \\
\text { spontaneum }\end{array}$ & 6885 & 956 & 13 & 98 \\
\hline
\end{tabular}

BAC contigs. These sequences shared similar synteny blocks, suggesting that SES32E01 and SES69 K24 were allelic haplotypes in $S$. spontaneum. Similar results were observed in SPSA, SPSB and SPSC (Table 1). The SPS orthologs in the two species were highly similar, with sequence identities ranging from 95.6 to $100 \%$ under the pairwise comparison (Additional file 5 ).

To further compare the SPS allelic haplotypes, we compared the exon-intron structures of the 14 SPS sequences in $S$. officinarum and S. spontaneum (Fig. 1a). The SPS genes were clustered together and the alleles are indicated with a, b or c. As expected, most orthologous/paralogous pairs showed similar exon-intron structure. For instance, three SPSC alleles (SoSPSC.a, SoSPSC.b and SoSPSC.c) were identified in S. officinarum and one allele (SSSPSC.a) was identified in S. spontaneum. Despite the overall similarity in gene structure, frequent divergence was also observed among the orthologs and haplotypes, though these proteins were highly conserved at amino acid level. We observed longer gene length and more exons (11 v.s. 9) in SsSPSA.a compared to SoSPSA.a. Notably, one exon was inserted after the second exon in SSSPSA. $a$ and this gene appeared to possess an additional exon at the end of sequence. In addition, we identified three SPSB sequences (SoSPSB.a, SoSPSB.b and SsSPSB.a) in S. officinarum and S. spontaneum. SoSPSB.a and SsSPSB.a showed highly similar exon-intron structure, while the allelic haplotype SoSPSB. $b$ was quite divergent compared to other SPSBs. SoSPSB. $b$ was shorter in gene length and possessed fewer exons compared with SoSPSB.a and SsSPSB.a. This could be due to allelic variation or more likely resulted from incomplete genome assembly. Similar results were also observed in SPSD1. Exons in SsSPSD1.b tended to be shorter and fewer in number than in SSSPSD1. $a$ and SoSPSD1.a.

Furthermore, we annotated the transposable elements (TEs) within the introns of the SPS genes (Fig. 1a). Four SPS members with the exception of SPSB were revealed to contain TE. TE insertions existed in the second intron of SPSC and the last intron of SPSD2 in S. officinarum but were absent in $S$. spontaneum. In addition, a large TE was present in SPSD1 from S. spontaneum, suggesting genomic expansion of SPS genes existed in $S$. spontaneum.

\section{Multiple alignment analysis}

We performed a multiple alignment analysis for the Saccharum SPS genes and regions of interest were marked with red rectangles, including light-regulated phosphoserine, putative F-6-P binding site, 14-3-3 regulated phosphoserine and UDP-Glu binding domain, osmotically regulated phosphoserine and various aspartateproline pairs (Fig. 1b). High sequence similarity was observed in the middle part of SPS proteins. As expected, the F-6-P binding sites and UDP-Glu binding domains are highly conserved at the amino acid level (Fig. 1b, II and III) in most sugarcane SPS proteins. Similarly, the osmotically regulated phosphoserine (IV) and various aspartate-proline pairs (V, VI and VII) are conserved as 


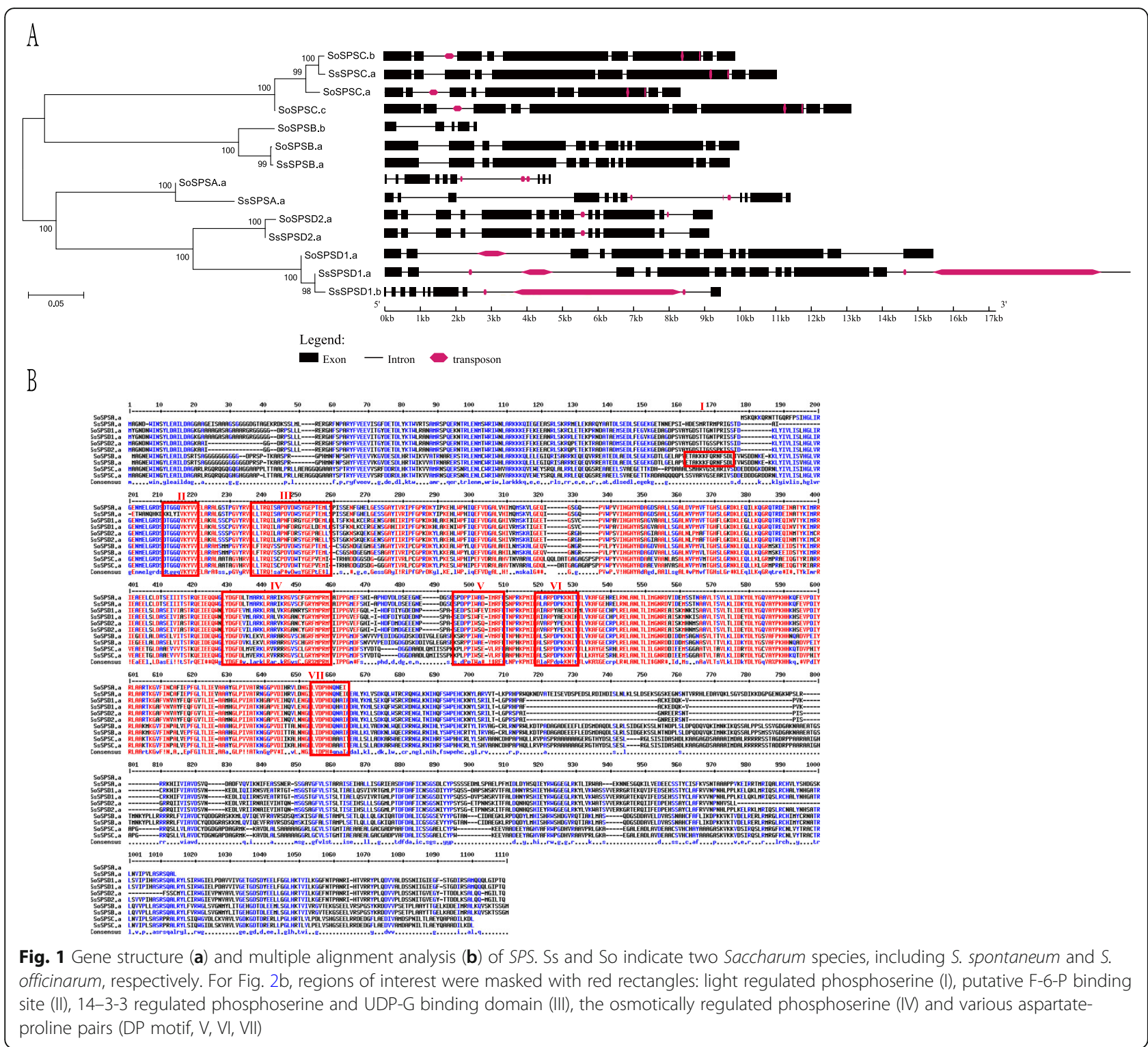

well, suggesting that these regions play important roles in sugar production. We also observed some mutations that may differentiate the functions of SPS proteins. For instance, a couple of mutations in the SsSPSA F-6-P binding domain (II) likely modified its F-6-P binding activity. A conversion from Serine (S) to Leucine (L) in SPSD family possibly influenced its function in UDP Glu binding (III). Remarkably, light regulated phosphoserines (I) were highly divergent, suggesting that the SPS genes played different roles in response to light regulation. We further investigated the cis-elements in the promoters of the 14 SPS genes (Additional file 6). Cis-elements that are related to the circadian clock, such as circadian and E-box, were observed in most of Saccharum SPSs. In addition, cis-elements involved in abiotic stress were predicted in the promoter region. For instance, ABREs (ABA-responsive elements) were identified in 6 SPS promoters and MYB-binding sites (MBSs) were found in 11 SPS promoters. These results suggested that Saccharum SPS genes might be regulated by the circadian clock and abiotic stress.

\section{Phylogenetic and evolutionary analysis of SPS genes in plants}

To further investigate the evolutionary history of sugarcane SPS genes, we first analyzed SPS genes from two dicotyledonous plants (including Arabidopsis thaliana and Vitis vinifera), five monocotyledonous plants (including 
Ananas comosus, S. bicolor, Brachypodium distachyon, Zea mays and Oryza sativa) and a sole surviving sister species of all other living flowering plants (Amborella trichopoda) (Fig. 2a). All the Saccharum SPS genes identified in this study including alleles were included in the phylogenetic analysis (Fig. 2b). The result showed that selected plant SPSs were clustered into 4 classes (SPSA, $S P S B, S P S C$ and SPSD). Similar to a previous study [4], $S P S A, S P S B$ and SPSC sub-families are present in both monocotyledonous and dicotyledonous plants; while the $S P S D$ gene family only exists in monocotyledonous plants. This result indicated that SPSD genes emerged more recently after the monocot-dicot divergence. In addition, the SPSD gene family had a closer phylogenetic relationship with SPSA than SPSB and SPSC. In $A$. trichopoda, we only identified two SPS genes (SPSA and SPSC) (Fig. 2a).

The non-synonymous to synonymous substitution rate $(\mathrm{Ka} / \mathrm{Ks})$ is an indication of selective pressures. A $\mathrm{Ka} / \mathrm{Ks}$ ratio $<1$ is consistent with a history of negative selection, while $\mathrm{Ka} / \mathrm{Ks}$ ratio $>1$ indicates a strong positive selection [26]. We performed a pairwise comparison within each SPS gene from selected plants (Fig. 2c). Almost all SPS genes showed that $\mathrm{Ka} / \mathrm{Ks}$ values were lower than 1, suggesting that these family members were under strong purifying selection. To further identify the evolutionary forces acting on the sugarcane SPS genes after the divergence of $S$. officinarum and $S$. spontaneum, we investigated the $\mathrm{Ka} / \mathrm{Ks}$ values of SPS genes in S. bicolor, $S$. officinarum and S. spontaneum (Additional file 7).

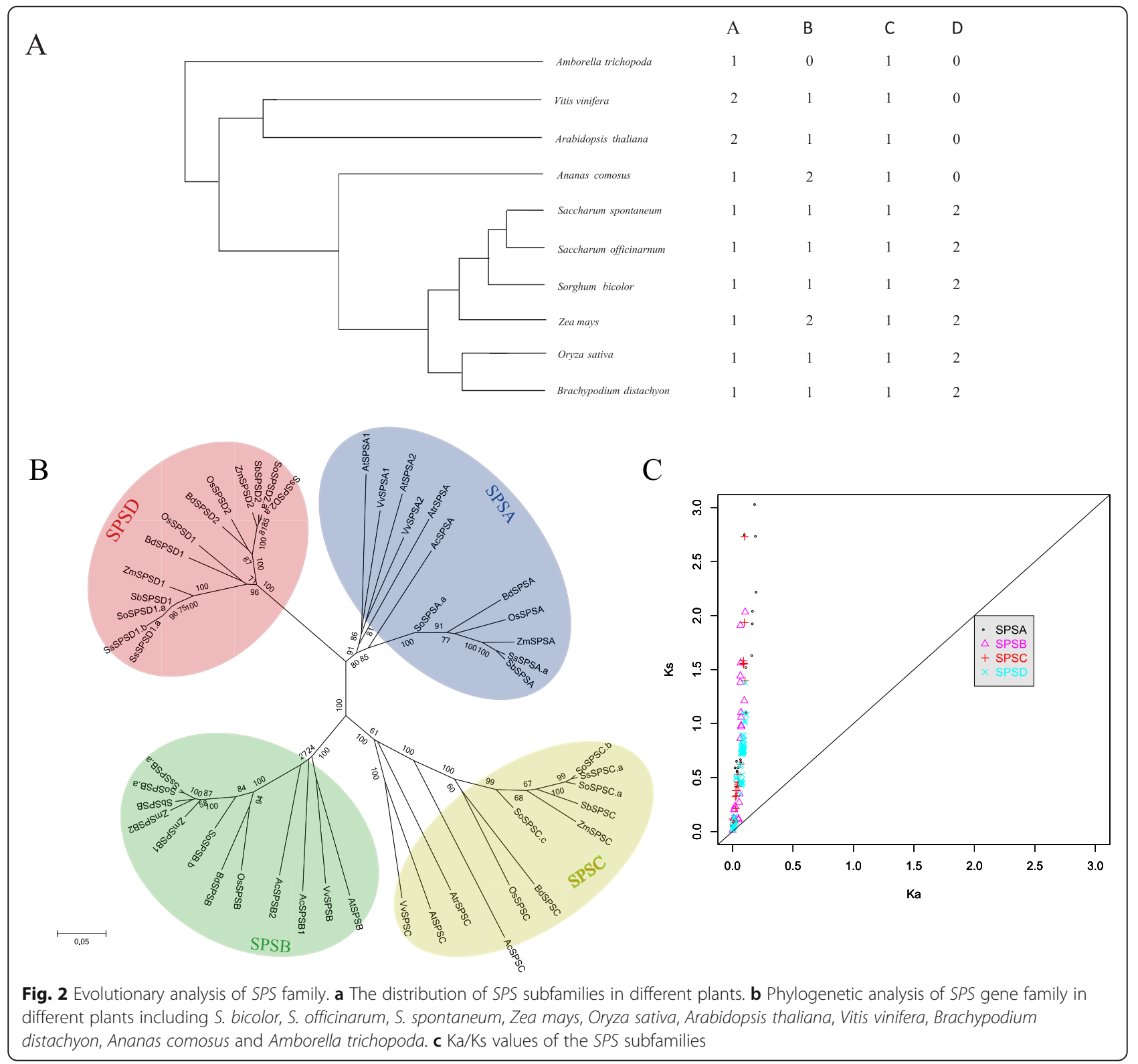


Expression profiles of SPS genes in the different tissues of three developmental stages

To investigate the expression pattern of SPS gene families, two transcriptome databases (See materials and methods for details) were used for the expressional analysis from two Saccharum species (S. spontaneum and $S$. officinarum).

The expression of SPS genes at three different developmental stages (seedling, pre-mature stage and mature stage) were clustered into two trends, demonstrating the significant expressional preference in the stem or leaves of the two species (Fig. 3). One trend is that the genes were much more highly expressed in leaves opposed to the stem, including SPSB and SPSC genes at these three developmental stages, which was consistent with a previous study [27]. Furthermore, SPSB expression was higher than $S P S C$, indicating that SPSB was the dominant gene expressed in the leaves and functioned in the green tissues of the two Saccharum species. The other trend is that the genes were expressed at significantly higher levels in the stem compared to those in leaves at all developmental stages, in particularly SPSA, SPSD 1 and SPSD2 in S. officinarum and S. spontaneum. Similarly, SPSA was the major gene specifically expressed in the stem, especially at the mature stage, which is similar to a previous study that one sugarcane SPS gene was expressed in internodes [17]. Meanwhile, SPSA gene was the highest expressed of all SPS genes and higher in $S$. officinarum than in S. spontaneum, suggesting SPSA may play an important role in the transportation and storage of sugarcane sugar.

Interestingly, $S P S B$ expression level was higher in the leaves of $S$. officinarum compared with $S$. spontaneum at the pre-mature stage, while more SPSA transcripts accumulated in the internodes of $S$. officinarum at the mature stage than S. spontaneum (Fig. 3), suggesting the differential expressions of SPSA and SPSB may contribute to the differences in sugar yields between $S$. officinarum and S. spontaneum.

\section{Expression profiles of SPS genes in the segments of developmental gradients in leaves}

Based on the above findings, the present study further analyzed the SPS expression patterns in the segments of development gradients in leaves and discovered that certain expressional patterns in almost all genes in these two species (Fig. 4a). We found that SPS gene expressions in S. spontaneum were consistent with the continuous developmental gradient in leaves, while there were three small peaks in S. officinarum (Fig. 4b). In additional, the higher specific expression of SPSB in the leaves of the two species were demonstrated (Fig. 4).

Interestingly, the SPSC expression level was lower than $S P S B$ although the expression patterns were similar, indicating that the functions of SPSB and SPSC were complementary. Furthermore, this study also found that the SPSA, SPSC and SPSD2 genes in S. spontaneum had higher than those in S. officinarum, relatively (Fig. 4a).

\section{SPS protein levels in the two Saccharum species}

To further explore the SPS protein levels in sugar synthesis source tissue (leaf) and sucrose accumulation sink tissue (stem), we performed proteomics analysis on a gradient in developing leaves and mature stem tissues (Fig. 5). In leaves, the relative protein content $(\log 2$ the intensity of protein) of SPSB was highest among the gene families, which was consistent with transcriptome data. The content of SPSD2 was much higher than that of SPSB, but only slightly higher than SPSC. The protein content of SPS only presented very limited variation

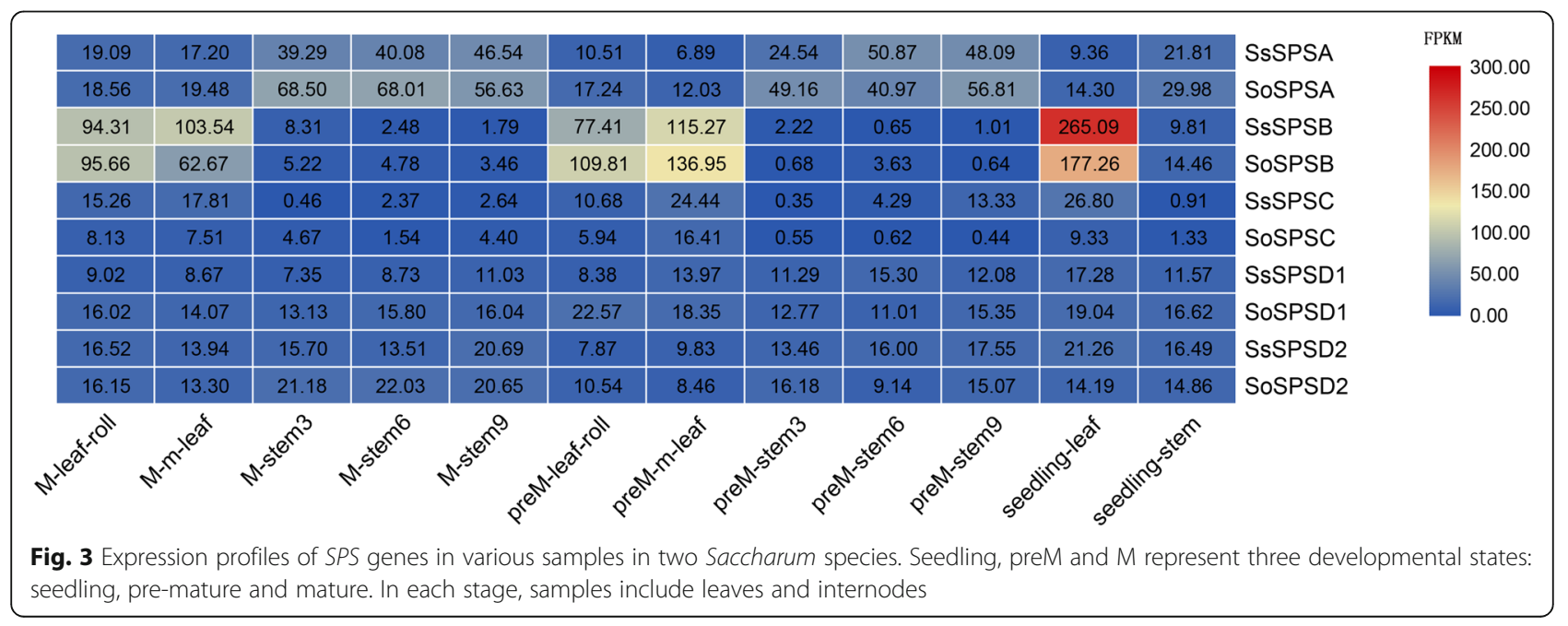




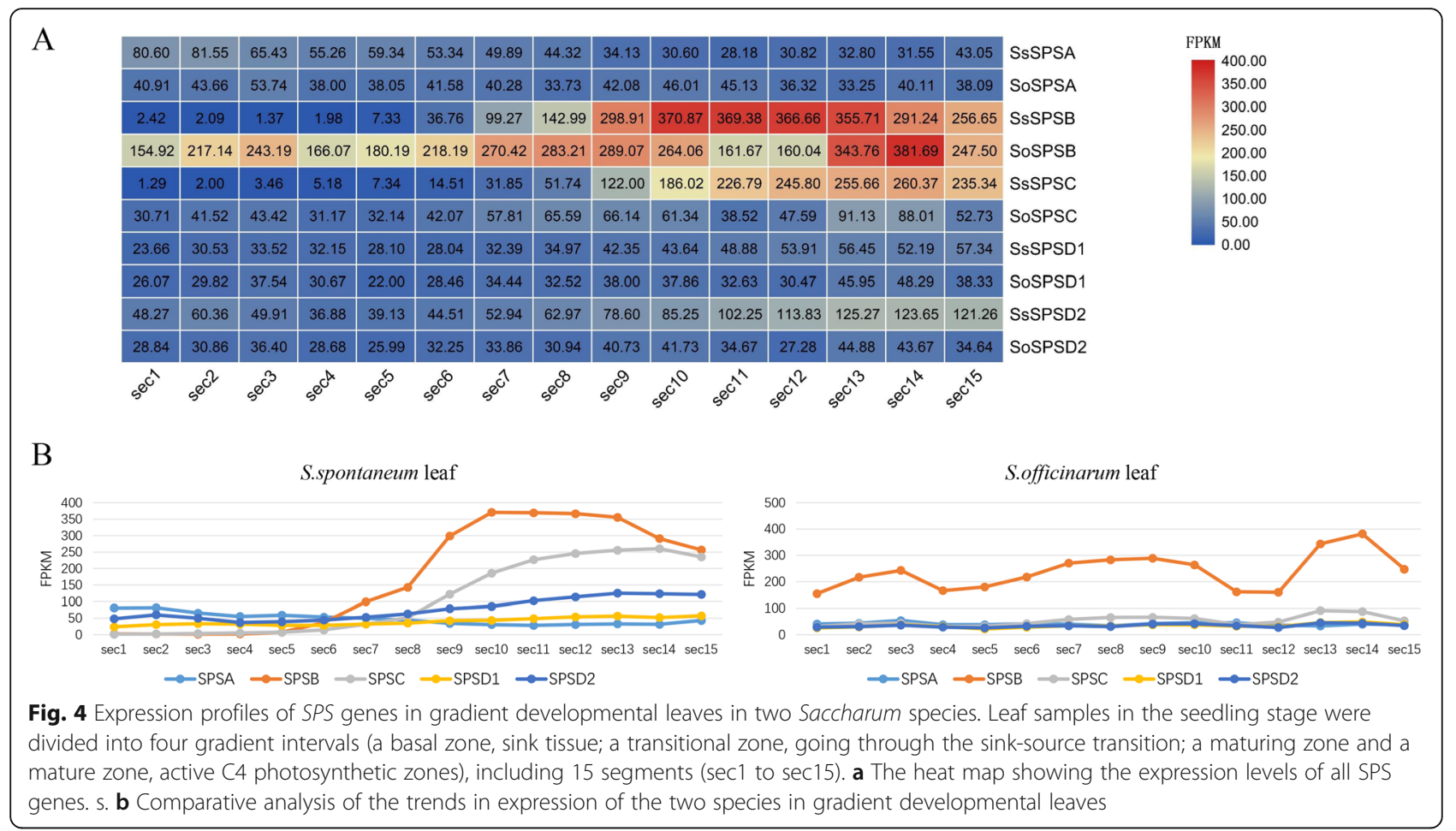

between the two Saccharum species, except for SPSD1. The protein contents of the SPS gene families in stem were much different from those in leaf tissue, supporting the theory that SPSs are involved in the distribution of sugar. Importantly, in stem tissue SPSC and SPSD2 presented protein levels similar to leaf tissue, while, SPSB and SPSD1 were much lower than in leaf. These results suggested that the SPSB and SPSD1 contributed to the synthesis of sugar rather than SPSC and SPSD2. In addition, SPSA protein was undetectable in the examined tissues of these two Saccharum species, indicating the limited contribution of SPSA.

\section{Sugar contents in the two Saccharum species}

To further analyze the SPS functions in sugarcane, metabolomics analysis was carried out and the changes in small molecule concentrations that were closely related to the phenotype of sucrose trait in two Saccharum species were examined. Based on the two sets of metabolome data from leaves at seedling and stems at mature stage, there were two metabolites, which were directly associated with SPS enzymes, F-6-P (a substrate during SPS catalyzing the synthesis of sucrose) and sucrose (end products of SPS catalytic pathway).
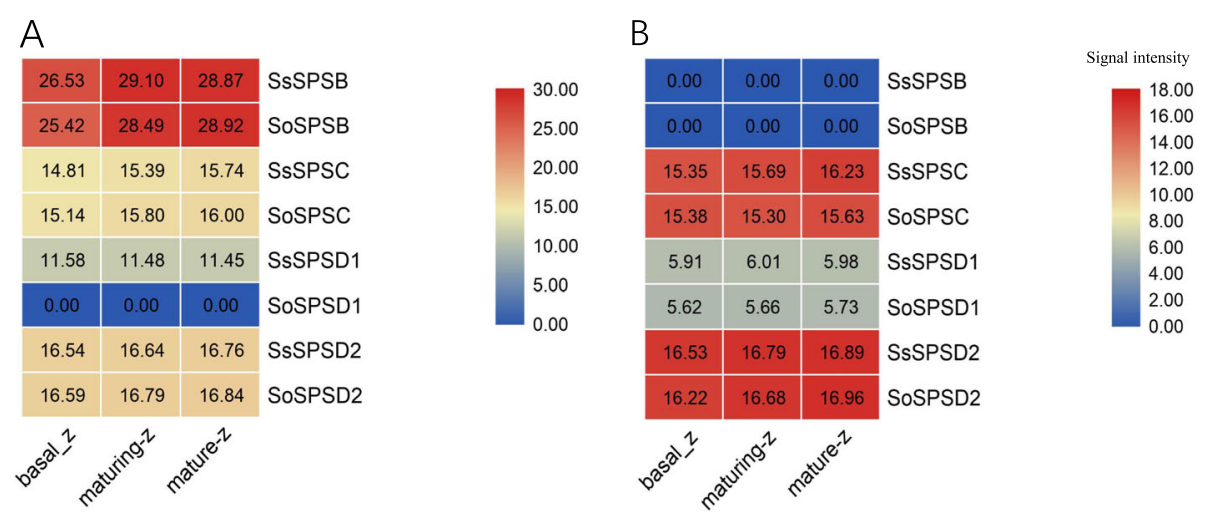

Fig. 5 The relatively content of SPS protein in gradient developmental leaves (a) and stems (b) in two Saccharum species. The developmental leaves and stems were all divided into three developmental blocks: basal-zone (basal-z), maturing-zone (maturing-z), mature-zone (mature-zone) 
For the gradient of developing leaf, an increasing trend of sucrose content was found in S. officinarum and $S$. spontaneum as the leaves became into mature (Fig. 6a), while a generally decreasing trend of F-6-P content was found in the two species, indicating SPS performed the same functions during the sucrose synthesis in the two varieties. For the stems at different developmental states, sucrose content showed different tendencies among three species, such as a significant increase in S. officinarum and increasing from young stems to the maturing zone and then declining from the maturing zone to the mature zone in S. spontaneum (Fig. 6b). The levels of F6-P were almost not detectable in three stem nodes from both $S$. officinarum and S. spontaneum. Whereas the sucrose contents in the seedling leaf and the stems were higher in S. officinarum than in S. spontaneum.

\section{Discussion}

\section{Gene evolution of SPS family}

In this study, we used an extensive collection of plant SPS gene members for phylogenetic analysis, and the results confirmed the previous classification [4], and revealed the existence of three groups $(S P S A / B / C)$ containing both monocotyledonous and dicotyledonous and one Poaceae species specific SPSD (Fig. 1b). A. trichopoda only contained two SPS genes (AtrSPSA and AtrSPSC), suggesting that SPSB newly evolved after the divergence of $A$. trichopoda and other flowering plants (Fig. 2a). The evolutionary history of Saccharum SPS, which was sorted chronologically, from ancient to more recent, was SPSA/SPSC, SPSB, SPSD1/SPSD2.

Previous studies showed that SPSD genes emerged after the monocot-dicot divergence [28]. In our study, phylogenetic analysis more precisely showed that the SPSD genes likely evolved from the SPSA clade (Fig. 2b) and were clustered into two groups, SPSD1 and SPSD2.Interestingly, SPSD genes only existed in Poaceae plants rather than in $A$. comosus, which was an out group to the Poaceae lineage in the Poales order [29], suggesting that SPSD genes evolved separately within the Poaceae clade. Within the coding regions, the $\mathrm{Ka} / \mathrm{Ks}$ ratios of SPSD genes were much less than 1, indicating that purifying selection was the dominant force driving the evolution of SPSD genes after the speciation of the two Saccharum species. Molecular evolution analysis revealed that negative selection drove the evolution of these genes, suggesting their functional importance.

Sorghum is the closest relative in the diploid genera of Saccharum. Comparative analysis of the orthologs between Sorghum and Saccharum made it possible to investigate the specific evolutionary events after the polyploidization of Saccharum. Previous studies indicated that polyploidy was a powerful player in the acceleration of evolutionary adaptation [30]. One research group detected the rapid spread of beneficial mutations in tetraploid yeast in response to growth on a poor carbon source [31]. To investigate the evolutionary pressure of SPS genes in polyploidy Saccharum, we calculated the $\mathrm{Ka} / \mathrm{Ks}$ ratios in $S$. bicolor, S. officinarum and S. spontaneum (Additional file 7). Almost all the pairwise comparisons of $\mathrm{Ka} / \mathrm{Ks}$ that were statistically significant were lower than 1 (Fisher test, $p<0.05$ ), indicating that SPS genes in Sorghum and Saccharum were undergoing purifying selection. However, the $\mathrm{Ka} / \mathrm{Ks}$ ratios within $\mathrm{Sac}$ charum were significantly higher than between Sorghum and Saccharum (mean $=0.22$ versus mean $=0.12$, MannWhitney-Wilcoxon test, $p=0.01775$ ). This result showed that polyploidy relaxed selection pressure of SPS genes in Saccharum, which is an expected outcome of gene redundancy in the polyploids.

\section{TEs influence the evolution of SPS genes}

$\mathrm{TE}$ are a dominant feature of most flowering plant genomes and greatly contribute to genome evolution and diversity [32]. TEs are known to have a cis-effect on gene regulation since the likely DNA and histone methylation are often associated with the repetitive sequences. A previous study showed that high levels of TE variation was observed between $S$. officinarum and S. spontaneum [33]. In our research, comparison of SPS genes between the two sugarcane species displayed frequent TE variation, indicating that TEs could play important roles in SPS evolution before and after the divergence of $S$. officinarum and S. spontaneum. For instance, two adjacent
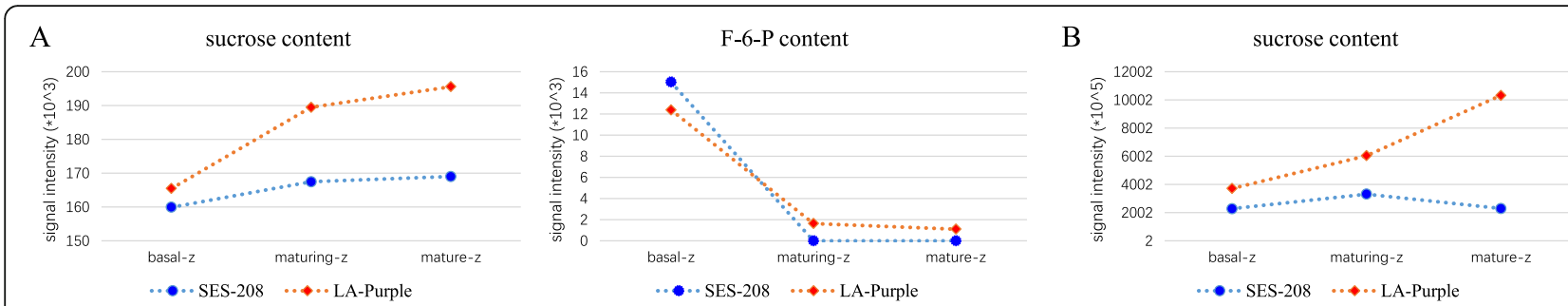

Fig. 6 Metabolomics analysis in gradient developmental leaves (a) and stems (b) in two Saccharum species. The sampling methods are consistent with the proteomics analysis. The comparative analysis of the metabolites of sucrose and fructose-6-phosphatein in leaves and stem internodes of two species were performed, Fructose - 6-phosphate was not detected in the stems of either species 
TEs were inserted into the seventh exon of SoSPSC.a, SoSPSC. $b$ and SsSPSC.a, suggesting that the events happened before the divergence of the two sugarcane species (Fig. 2a). However, another TE insertion event was only observed in the second intron of SoSPSC.a and SoSPSC. $b$ rather than SsSPSC.a, suggesting that SPSCs were undergoing independent evolution after divergence of the two Saccharum species.

$S P S D$ genes were unique in monocots and our results uncovered that they were likely undergoing quite different evolution fate. SoSPSD2. $a$ and SsSPSD2. $a$ were conserved in exon-intron order, gene length as well as TE distribution (Fig. 2a). However, it seemed that gene structure of SPSD1 was less conserved and the last exon of SSSPSD1.a was interrupted by a large TE insertion. Moreover, the SSSPSD1.b displayed a quite different exon-intron structure as well as a large TE variation compared to its allelic haplotype SsSPSD1.a. These results demonstrated that the two copies of newly evolved SPS subfamily tended to be functional diverse in sugarcane and possibly TE variation was responsible for the diversity, providing the first evidence that TE contributed to gene evolution in Saccharum.

\section{Functional divergence of SPS genes between $S$. officinarum and S. spontaneum}

RNA-seq analysis revealed that the expression of $S P S B$ in S. officinarum leaves were higher than that in S. spontaneum leaves at the pre-mature stage (Fig. 3). Furthermore, the expression of SPS in leaves displayed consistent trend between these two Saccharum species as a developmental gradient progressed (Fig. 4), indicating that the expression of SPS was responded to photosynthesis in the seedling leaf.

SPSB presented consistently high expression in $S$. officinarum which was consistent with the highest relative content of SPSB protein based on proteomics analysis, indicating SPSB may be the major gene of sucrose synthesis in leaf. Combined with metabolome data, we found in leaves at the seedling stage that sucrose increases and F-6-P decreases, which was in line with the trend of expression of SPS (especially the SPSB gene with high expression level) mentioned above which catalyzes the synthesis of sucrose using substrate of F-6-P. Therefore, in the source tissue leaves, we speculate that SPS genes play a key role in sucrose synthesis which is linked with the development of leaves in these two Saccharum species. Further correlation analysis revealed there were significant overall relationships between the expression of SPSB and the content of sucrose (positive, $\mathrm{r}^{2}=0.97$ or 0.93 ) or F-6-P (negative, $\mathrm{r}^{2}=0.84$ or 0.90 ) both in $S$. officinarum and in $S$. spontaneum (Additional file 8). Since the characteristics of high and low sugar in cultivated sugarcane were respectively contributed by $S$. officinarum and $S$. spontaneum, the gene expression of SPSB may play a significant role in sucrose synthesis and accumulation. These results revealed that SPSB played a vital role in sugarcane leaves and they might be responsible for the difference of sugar at the production process of growth. However, considering the limited data points for correlation analysis, further verification of experimental data is required to support this speculation.

Besides SPSB, SPSA also showed different expression patterns at seedling and mature stages between the two species (Fig. 3). SPSA was expressed at higher levels in $S$. officinarum stems than in S. spontaneum stems, which may be caused by different gene structures given that there are 9 exons in SoSPSA and 11 exons in SsSPSA (Fig. 1a). Interestingly, when the expression of SPSA in different segments of the developing stem and metabolites were compared, a significant nonlinear negative relationship did exist among three species, except for one special case in S. spontaneum in which the sucrose content was to some extent correlated with the expression of SPSA $\left(\mathrm{r}^{2}=0.84\right.$ or 0.90$)$ in the stem (Additional file 8 ). This indicates that there could be other genes regulating sucrose synthesis in stem tissue or other influencing factors, resulting in differences in sucrose content in stems of the three species. Considering the lower expression of SPS genes in stem tissue than in leaf tissue and the higher expression levels of SPS genes in S. officinarum than in S. spontaneum, lower levels of sucrose synthesis in stems and high sucrose content in stem were mainly obtained through sugar transport rather than sugar synthesis.

The results revealed that SPSD duplicated within the Poaceae lineage. The gene expression data revealed that the two SPSDs had similar expression patterns, suggesting functional similarity in this gene subfamily. Furthermore, SPSD maintained similar lower expression levels in all tissues of sugarcane and there are no specific expressive features, which is different from wheat SPS genes but consistent with the research in sugarcane [34]. However, both SPSD gene copies were under strong purifying selection shown by their $\mathrm{Ka} / \mathrm{Ks}$ ratio $<0.4$ (Additional file 7), which demonstrated that the two SPSDs were not functionally redundant in Saccharum. Therefore, we assumed that two SPSD subfamilies shared similar gene functions while possessing divergent key functional roles in Saccharum. Proteome data showed that the protein content of SPSD2 was highest in the developing stem and SPSA protein was not detected in leaves and stem internodes. Combined with the recent replication events in which SPSD evolved from SPSA and the high levels of SPSA gene expression in the stem, we suspected that the high SPSA expression levels in stem tissue regulates the translation of the highly 
homologous genes of SPSD, which lead to the high protein levels of SPSD2 and free protein content of SPSA in stem tissue in both two species.

Interestingly, the present study found SPS expression was affected by photosynthesis and regulated by circadian rhythm. All SPS in the gradient of developing leaves displayed differing expression patterns, indicating SPS expression was synchronized with light assimilation in a species-specific manner (Fig. 4). Therefore, we assumed that the SPS contributed to the differential sugar accumulation between the two Saccharum species. Notably, SPS expression was sometimes regulated by other enzymes, for example, SPS had potential functions and contributed to sucrose synthesis when soluble acid invertase (SAI) was low [35].

Meanwhile, based on the high spatiotemporal specificity of SPSB and SPSA in the SPS gene family and the simultaneous comparative analysis of transcriptomes, metabolomes and proteomes, we suspect that the regulation of SPSB and SPSA gene expression are an important point in the formation of regulatory networks in sucrose traits among different species of Saccharum. Furthermore, sucrose accumulation is a complex process requiring the involvement of multiple genes for sugar synthesis, transport and the targeting regulation. In this way, different patterns of expression of SPS genes may be formed among different sugarcane species, leading to different levels of photosynthetic carbon fixation and even different sugar traits.

\section{Conclusions}

We presented a comprehensive analysis of SPS genes in two Saccharum species, including S. spontaneum and $S$. officinarum. By analyzing and comparing these SPS genes, we concluded three major findings. Firstly, frequent structural variations and mutations were observed in SPS homologs as well as allelic haplotypes. In addition, comparison of SPS genes between the two Saccharum species displayed several TE insertion/deletion events, indicating that TEs might play important roles in $S P S$ evolution before and after the divergence of the two species. Secondly, the SPSD subfamily in Saccharum was newly evolved from SPSA after the generation of Poaceae species. Molecular evolution analysis showed that all the SPS genes were under negative selection and selection pressure was reduced under the process of polyploidy. Thirdly, RNA-seq, metabolome and proteome data uncovered the different expression patterns of the SPS gene family between $S$. officinarum and S. spontaneum, suggesting that SPSA and SPSB are possibly responsible for the fundamental differences in sugar yields at different stages. The high expression of SPSB in developing leaves may play a direct and key role in sucrose synthesis at the source organization, and the accumulation of high sucrose levels In the stem there may be a more complex regulatory network in which SPSA and SPSD genes are indirectly involved.

\section{Methods}

Plant materials and RNA extraction

Sugarcane species LA-Purple [36, 37] (S. officinarum, $2 \mathrm{n}=8 \mathrm{x}=80$, originated in USA) and SES208 [38] ( $S$. spontaneum, $2 \mathrm{n}=8 \mathrm{x}=64$, originated in USA) [39, 40] that were deposited in the National Germplasm Repository of Sugarcane (Yunnan, China) and used in the present study. Plants were grown in plastic pots under greenhouse conditions $\left(14: 10 \mathrm{~L} / \mathrm{D}, 30^{\circ} \mathrm{C} \mathrm{L} / 22^{\circ} \mathrm{C}\right.$ D and $60 \%$ relative humidity) and standard growing practices in the sugarcane experiment field at Fujian Agricultural and Forestry University (Fuzhou, China). For the investigation of the different developmental stages and the gradient developmental leaf analysis experiments were performed as previously described [41]. Tissue of developmental leaf was collected $3 \mathrm{~h}$ into the $\mathrm{L}$ period as detailed by Li et al. [42] and the collection of other tissues was detailed by Ming et al. [29]

RNA from various sugarcane tissue samples were extracted using Trizol (Invitrogen, USA) according to the manufacturer's protocol. RNA was digested with DNase I (NEB, USA) and the RNA integrity was assessed using the Agilent Bio-analyzer 2100 system (Agilent Technologies, CA, USA).

\section{BAC libraries}

A list of BAC libraries were constructed from the haploid genome of $S$. spontaneum (AP85-441, 2n $=4 \mathrm{x}=32$ ) and S. officinarum (LA Purple, $2 \mathrm{n}=80$ ). Nuclei were isolated from young leaf tissues following the protocol in [43]. Briefly, high molecular weight DNA was extracted and digested into fragments with HindIII. Approximately $100 \mathrm{~kb}$ fragments were isolated and inserted into the pSMART BAC vector (Lucigene, LA). BAC clones which contained potential SPS genes were sequenced using an Illumina Hiseq 2500. There were 74,880 clones in BAC library of LA Purple based on 195-384 well plates with $150 \mathrm{~kb}$ of an average insert size, which provided the 1.5 $\mathrm{x}$ and $12 \mathrm{x}$ coverage of the octoploid genome and the monoploid genome, respectively. For AP85-441, the BAC library was consisted of 38,400 clones (in the 100 384 well plates with an average insert size at $120 \mathrm{~kb}$ ), which was an about $1.5 \times$ coverage of the haploid (tetraploid) genome and an about $6 \times$ coverage of the monoploid genome.

\section{Assembly, annotation of BAC reads and identification of SPS gene family}

The raw reads were assembled using SPAdes 3.6.2 with default parameters [44]. Firstly, we designed the probes 
using Sorghum SPS sequences (Additional file 9) and matched the probes against sugarcane BAC libraries. We then performed De novo assembly and gene annotation for the selected BACs. To get a better annotation, TEs and tandem repeat sequences were identified. The assembled contigs were screened using RepeatMasker [45] for TE annotation and to the DNA subway system (http://dnasubway.iplantcollaborative.org/) for coding region annotation using the model of "Annotate a genomic sequence" referring to the tips on the web page (https:// github.com/CyVerse-learning-materials/dnasubway_ guide). For TE identification, annotation was confirmed if there was at least $60 \%$ identity and a minimum length of $50 \mathrm{bp}$ with previously annotated plant TEs (ftp://ftp. plantbiology.msu.edu/pub/data/TIGR_Plant_Repeats/

).The corresponding coding sequences were translated into protein by the EXPASy-translate tool (http://web. expasy.org/translate/).

SPS homologs from other plants, such as Arabidopsis, maize and so on, were downloaded from NCBI (http:// www.ncbi.nlm.nih.gov/). A blast-based search was performed to identify SPS gene family from S. officinarum and S. spontaneum, as well as selected plants listed in Additional file 5. The cutoff was set as E-value less than $10^{-20}$ and identity higher than $85 \%$.

\section{Gene structure, phylogenetic and evolutionary analysis}

The exon-intron structures were extracted from gene annotation data generated by DNA subway and further displayed in GSDS (Gene Structure Display Server) [46]. In addition, MultAlin [47] program was used to illustrate the multiple sequence alignment of amino acids and domains of interest for sugarcane SPS genes. Plant CARE (http:// bioinformatics.psb.ugent.be/webtools/plantcare/html/) was used to predict cis-elements in SPS promoters.

To generate a phylogenetic tree, the predicted protein sequences from seven plants, including two Saccharum species (S. officinarum and S. spontaneum), Zea mays, Sorghum bicolor, Arabidopsis thaliana, Brachypodium distachyon, Vitis vinifera, Ananas comosus, Oryza sativa and Amborella trichopoda were initially aligned based on Clustal W2.0 [48]. Then we reconstructed the phylogenetic tree of SPS genes by the Neighbor-Joining method estimated by the JTT amino acid matrix implemented using the program MEGA 4.0 [49]. The pairwise deletion option was set in the $\mathrm{NJ}$ tree reconstruction and the accuracy of the tree topology was assessed by bootstrap analysis with 1000 resampling replicates.

Genes of SPSA, SPSB, SPSC and SPSD were initially aligned using Clustal W2.0 [48]. The aligned sequences were subject to KaKs_Calculator [50] to calculate the Ka and Ks values.

\section{Expression analysis using RNA-seq data}

For two blocks of expression profile, the first batch of samples were from different tissues at three different developmental stages (seedling, pre-mature stage and mature stage), including 2 leaves (mature leaf and leaf roll) and 3 stalks (mature, maturing and immature stalk). In additional, the second batch of samples were segments of the gradient developmental leaf, which was divided into 15 clips in four zones: a basal zone (base, sink tissue), a transitional zone (going through the sink-source transition), a maturing zone and a mature zone (active $\mathrm{C}_{4}$ photosynthetic zones, fully differentiated).

Paired-end sequencing (100 bp reads length) was performed using the HiSeq 2500 platform. The raw data was obtained from a list of RNA-seq libraries and initially filtered using Trimommatic [51] with default parameters. Then Tophat program was performed to map clean reads to assemble BAC contigs and the FPKM values for each SPS gene were calculated using cufflinks [52].

\section{Metabolomics experiments}

Leaves in seedling and stems in the mature stage were sampled from two species, LA-Purple (S. officinarum), SES 208 (S. spontaneum), respectively. For the leaf samples, we selected three segments during different developmental stages, 0-2 segments (basal zone), 7-9 segments (maturing zone) and 13-15 segments (mature zone). For stem samples, the internodes selected were the same as in the experiments involving RNA-seq, three zones (basal zone, maturing zone, mature zone), stem 3 , 6, 9 in S. spontaneum and stem 3,9,15 in S. officinarum. Samples were harvested and ground with a ball mill precooled with liquid nitrogen, brought back to extract and derivatize the metabolites. Chromatographic analyses of derivatized samples were achievedusing a random injection sequence, on an Agilent 7890B GC (Agilent, Atlanta, GA, USA), coupled to a Pegasus HT time-of-flight mass spectrometer (LECO, St. Joseph, MI, USA), equipped with a Gerstel MultiPurpose Sampler (MPS) (Gerstel, Mülheim an der Ruhr, Germany). Five experimental replicates of each tissue were tested. Raw data was processed using ChromaTOF (version 4.51.6, LECO, St. Joseph, MI, USA) to identify the metabolites. Signal redundancy per metabolite was manually corrected and based on the normalized mean area of selected ions, quantitative measurements of analytes were performed after normalization using the IS. Next, by matching the mass spectra with those of authentic standards, public and commercial databases (NIST, Fiehn and Golm metabolome databases), the metabolites were identified. Chemical standards were purchased from Sigma (St. Louis, MO, USA) or Fluka (Milwaukee, WI, USA). For comparing the abundances of metabolites, the data matrix consisting of mass features and peak area values 
were exported from ChromaTOF to Excel. The mean peak area abundance values from five technical replicates were calculated after normalization to IS [53].

\section{Proteomics experiments}

To investigate the proteomic changes among two sugarcane species, the leave and stem samples analyzed were of the same stage as those used for the metabolomics experiments. To prepare the protein, one gram of fresh tissues was collected and the experimental method was referred to the FASP procedure [54] and the manufacturer's instructions (Thermo Fisher Scientific) following the TMT labeling procedure. We then prepared the sample to be fractionated by the strong cation exchange (SCX) chromatography as previously described [55]. On a nanoflow HPLC (Proxeon Biosystems, now Thermo Fisher Scientific), we performed RP-HPLC separation. The resolution for MS/MS spectra was set to 17,500 at $\mathrm{m} / \mathrm{z} 200$ and the normalized collision energy was $29 \%$. Reporter ion quantitation was based on the extraction of the TMT reporter ion signals of each peptide by MaxQuant software. The contents of proteins with the value of peak area were then quantified by summing reporter ion counts across all peptide matches, and then normalized by assuming equal protein loading across all samples.

\section{Supplementary information}

Supplementary information accompanies this paper at https://doi.org/10. 1186/s12870-020-02599-7.

\footnotetext{
Additional file 1. Gene annotation of BAC assembly.

Additional file 2. Gene identification of SPS genes in the S. spontaneum genome by Blastp with the sequence of SPS genes from BAC libraries. Two genes (Sspon.007C0001731 and Sspon.004A0021251) were reannotated.
}

Additional file 3. The protein sequences of SPS genes in S. spontaneum genome.

Additional file 4. Syntenic comparison of genomic DNA containing SPS genes among S. officinarum, S. spontaneum and S.bicolor. Homologs are indicated by arrows with same color. The asterisks indicate single-copied genes in the selected gene set.

Additional file 5. Pairwise comparison of SPS homologs in Saccharum.

Additional file 6. Cis-elements in SPS promoters.

Additional file 7. Ka, Ks comparison of SPS orthologs/alleles in S.bicolor, S. officinarum and S. spontaneum.

Additional file 8. Correlation analysis between the expression of SPS genes and content of the metabolites in gradient developmental leaves ( $A$, left) and stems (B, right) in Saccharum. The correlation coefficient $\left(R^{2}\right)$ and dependent equation of each groups data is marked near the correlation curve. $\mathrm{R}^{2}>0.9$ was considered to be significantly correlated.

Additional file 9. The information for probes used to identify SPScontaining BACs.

\section{Abbreviations}

ABREs: ABA-responsive elements; Developmental blocks: Basal-zone (basal-z), maturing-zone (maturing-z), mature-zone (mature-z); Developmental states: Seedling (seedling), pre-mature (pre-M), mature (M); F-6-P: Fructose-6-
Phosphate; GS: Glutamine synthetase; GSDS: Gene Structure Display Server program; LTR: Long Terminal Repeat; MBSs: MYB-binding sites; Ka/Ks: Nonsynonymous to synonymous substitution rate; ORFs: Open reading frames; SPS: Sucrose phosphate synthase; S-6-P: Sucrose-6-Phosphate; SPP: Sucrose phosphate phosphatase; Ss: Saccharum officinarum, S. officinarum; So: Saccharum spontaneum, S. spontaneum; SAI: Soluble acid invertase; TEs: Transposable Elements; UDP-G: UDP-Glucose

\section{Acknowledgements}

We are grateful for Dr. Xiaomin Feng for the invaluable insights and language editing.

\section{Declarations}

We declared that two Saccharum species used for this study do not require application for special permissions.

\section{Authors' contributions}

JZ designed the project. PM, LC, QY, MZ, XH and JZ performed the experimental analysis. PM, XZ, QZ, QZ, ZW and JZ performed the bioinformatics analysis. XZ, JZ, PM, ZW and HT wrote the manuscript. All of the authors have read the manuscript and approved the submission.

\section{Funding}

This work was supported by the Science and Technology Planting Project of Guangdong Province (2019B020238001), National key research and development program (2018YFD1000104); the National Natural Science Foundation of China (31201260, 31760413 and 31660420); the Science and Technology Major Project of Guangxi (GK2018-266-Z01); and the Fujian Provincial Department of Education (No. JA12082). The funders had no role in study design, data collection and analysis, decision to publish, or preparation of the manuscript.

\section{Availability of data and materials}

The 14 assembled BAC contigs were submitted to NCBI with the accessions KU685404-KU685417. Phylogenetic data (the alignments and phylogenetic trees) have been deposited to TreeBase and are accessible via the URL: http://purl.org/phylo/treebase/phylows/study/TB2:S19156.

Ethics approval and consent to participate Not applicable.

\section{Consent for publication}

Not applicable.

\section{Competing interests}

The authors declare that they have no competing interests.

\section{Author details}

${ }^{1}$ Center for Genomics and Biotechnology, Haixia Institute of Science and Technology, Fujian Provincial Key Laboratory of Haixia Applied Plant Systems Biology, College of Crop Science, Fujian Agriculture and Forestry University, Fuzhou 350002, China. ${ }^{2}$ Institute of Applied Ecology, Fujian Agriculture and Forestry University, Fuzhou 350002, China. ${ }^{3}$ College of Life Sciences, Fujian Normal University, Fuzhou 350007, China. ${ }^{4}$ Texas A\&M AgriLife Research, Department of Plant Pathology and Microbiology, Texas A\&M University System, Dallas, TX 75252, USA. ${ }^{5}$ Guangxi Key Lab of Sugarcane Biology, Guangxi University, Nanning, Guangxi, China. ${ }^{6}$ Department of Plant Biology, University of Illinois at Urbana-Champaign, Urbana, IL 61801, USA.

Received: 25 November 2019 Accepted: 13 August 2020

Published online: 14 September 2020

\section{References}

1. Koch KE. Carbohydrate-modulated gene expression in plants. Annu Rev Plant Physiol Plant Mol Biol. 1996:47:509-40.

2. Ma P, Yuan Y, Shen Q, Jiang Q, Hua X, Zhang Q, Zhang M, Ming R, Zhang J. Evolution and expression analysis of starch synthase gene families in Saccharum spontaneum. Trop Plant Biol. 2019;12(3):158-73.

3. Maloney VJ, Park JY, Unda F, Mansfield SD. Sucrose phosphate synthase and sucrose phosphate phosphatase interact in planta and promote plant growth and biomass accumulation. J Exp Bot. 2015;66(14):4383-94. 
4. Langenkamper G, Fung RW, Newcomb RD, Atkinson RG, Gardner RC, MacRae EA. Sucrose phosphate synthase genes in plants belong to three different families. J Mol Evol. 2002;54(3):322-32.

5. Huber SC, Huber JL. Role and regulation of sucrose-phosphate synthase in higher plants. Annu Rev Plant Physiol Plant Mol Biol. 1996;47:431-44.

6. Geigenberger P, Stitt M. A "futile" cycle of sucrose synthesis and degradation is involved in regulating partitioning between sucrose starch and respiration in cotyledons of germinating Ricinus communis $L$. seedlings when phloem transport is inhibited. Planta. 1991;1991(185):81-90.

7. Huber SC, Huber JL. Role of sucrose-phosphate synthase in sucrose metabolism in leaves. Plant Physiol. 1992;99(4):1275-8.

8. Leloir LF, Cardini CE. The biosynthesis of sucrose phosphate. J Biol Chem. 1955;214(1):157-65.

9. Reimholz R, Geiger M, Haake V, Deiting U, Krause K-P, Sonnewald U, Stitt M, et al. Plant Cell Environ. 1997;20:291-350.

10. Lunn JE. Sucrose-phosphatase gene families in plants. Gene. 2003;303:187-96.

11. Lutfiyya LL, Xu NF, D'Ordine RL, Morrell JA, Miller PW, Duff SMG. Phylogenetic and expression analysis of sucrose phosphate synthase isozymes in plants. J Plant Physiol. 2007;164(7):923-33.

12. Hawker JS. Enzymes concerned with sucrose synthesis and transformations in seeds of maize, broad bean and castor bean. Phytochemistry. 1971;10: 2313-22.

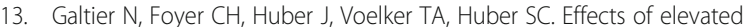
sucrose-phosphate synthase activity on photosynthesis, assimilate partitioning, and growth in tomato (Lycopersicon esculentum var UC82B). Plant Physiol. 1993;101(2):535-43.

14. Michallef BJ, Haskins KA, Vanderveer PJ, Roh K-S, Shewmaker CK, Sharkey TD. Altered photosynthesis, flowering, and fruiting in transgenic tomato plants that have an increased capacity for sucrose synthesis. Planta. 1995;1995: 327-34.

15. Seger M, Gebril S, Tabilona J, Pell A. Sengupta-Gopalan C: impact of concurrent overexpression of cytosolic glutamine synthetase (GS1) and sucrose phosphate synthase (SPS) on growth and development in transgenic tobacco. Planta. 2014;2015(241):69-81.

16. Zhang J, Zhou M, Walsh J, Zhu L, Chen Y, Ming R. Sugarcane genetics and genomics. In: Sugarcane: Physiology, Biochemistry, and Functional Biology; 2013. p. 623-43.

17. Verma AK, Upadhyay SK, Verma PC, Solomon S, Singh SB. Functional analysis of sucrose phosphate synthase (SPS) and sucrose synthase (SS) in sugarcane (Saccharum) cultivars. Plant Biol. 2011;13(2):325-32.

18. Chandra A, Verma PK, Islam MN, Grisham MP, Jain R, Sharma A, Roopendra K, Singh $K$, Singh P, Verma I, et al. Expression analysis of genes associated with sucrose accumulation in sugarcane (Saccharum spp. hybrids) varieties differing in content and time of peak sucrose storage. Plant Biol. 2015;17(3): 608-17

19. Mclntyre $\mathrm{CL}$, Jackson $\mathrm{M}$, Cordeiro $\mathrm{GM}$, Amouyal $\mathrm{O}$, Hermann $\mathrm{S}$, Aitken $\mathrm{KS}$, Eliott F, Henry RJ, Casu RE, Bonnett GD. The identification and characterisation of alleles of sucrose phosphate synthase gene family III in sugarcane. Mol Breed. 2006;18(1):39-50.

20. Mclntyre CL, Goode ML, Cordeiro G, Bundock P, Eliott F, Henry RJ, Casu RE, Bonnett GD, Aitken KS. Characterisation of alleles of the sucrose phosphate synthase gene family in sugarcane and their association with sugar-related traits. Mol Breed. 2015;35(3):98.

21. Sawitri WD, Narita H, Ishizaka-lkeda E, Sugiharto B, Hase T, Nakagawa A. Purification and characterization of recombinant sugarcane sucrose phosphate synthase expressed in E. coli and insect Sf9 cells: an importance of the N-terminal domain for an allosteric regulatory property. J Biochem. 2016;159(6):599-607.

22. D'Hont A, Rao PS, Feldmann P, Grivet L, Faridi N, Taylor P, Glaszmann J. Identification and characterisation of sugarcane intergeneric hybrids, Saccharum officinarum $x$ Erianthus arundinaceus, with molecular markers and DNA in situ hybridisation. Theor Appl Genet. 1995:91(2):320-6.

23. Fitch MM, Moore PH. Production of haploid Saccharum spontaneum L. comparison of Media for Cold Incubation of panicle branches and for float culture of anthers. J Plant Physiol. 1984;117(2):169-78.

24. Zhang J, Zhang X, Tang H, Zhang Q, Hua X, Ma X, Zhu F, Jones T, Zhu X, Bowers $J$, et al. Allele-defined genome of the autopolyploid sugarcane Saccharum spontaneum L. Nat Genet. 2018;50(11):1565-73.

25. Wang Y, Tang H, Debarry JD, Tan X, Li J, Wang X, Lee TH, Jin H, Marler B,

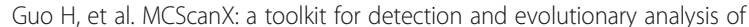
gene synteny and collinearity. Nucleic Acids Res. 2012;40(7):e49.
26. Yang Z, Bielawski JP. Statistical methods for detecting molecular adaptation. Trends Ecol Evol. 2000;15(12):496-503.

27. ElSayed Al, Lehrer A, Ebrahim M, Mohamed AH, Komor E. Assessment of sucrose transporters, metabolites and sucrose phosphate synthase in different sugarcane tissues. Physiol Mol Biol. 2017;23(3):703-12.

28. Castleden CK, Aoki N, Gillespie VJ, MacRae EA, Quick WP, Buchner P, Foyer $\mathrm{CH}$, Furbank RT, Lunn JE. Evolution and function of the sucrose-phosphate synthase gene families in wheat and other grasses. Plant Physiol. 2004; 135(3):1753-64

29. Ming R, VanBuren R, Wai CM, Tang H, Schatz MC, Bowers JE, Lyons E, Wang $\mathrm{ML}$, Chen J, Biggers $\mathrm{E}$, et al. The pineapple genome and the evolution of CAM photosynthesis. Nat Genet. 2015;47(12):1435-42.

30. Schoenfelder KP, Fox DT. The expanding implications of polyploidy. J Cell Biol. 2015;209(4):485-91.

31. Selmecki AM, Maruvka YE, Richmond PA, Guillet M, Shoresh N, Sorenson AL, De S, Kishony R, Michor F, Dowell R, et al. Polyploidy can drive rapid adaptation in yeast. Nature. 2015;519(7543):349-52.

32. Oliver KR, McComb JA, Greene WK. Transposable elements: powerful contributors to angiosperm evolution and diversity. Genome Biol Evol. 2013; 5(10):1886-901.

33. Garsmeur O, Charron C, Bocs S, Jouffe V, Samain S, Couloux A, Droc G, Zini C, Glaszmann JC, Van Sluys MA, et al. High homologous gene conservation despite extreme autopolyploid redundancy in sugarcane. New Phytol. 2011; 189(2):629-42.

34. Grof C, So C, Perroux J, Bonnett G, Forrester R. Research note: the five families of sucrose-phosphate synthase genes in Saccharum spp. are differentially expressed in leaves and stem. Funct Plant Biol. 2006:33(6):605-10.

35. Yun J, Zhu EK, Paul H. Moore: sucrose accumulation in the sugarcane stem is regulated by the difference between the activities of soluble acid Invertase and sucrose phosphate synthase. Plant Physiol. 1991;115:609-16.

36. Guimarães CT, Sills GR, Sobral BW. Comparative mapping of Andropogoneae: Saccharum L.(sugarcane) and its relation to sorghum and maize. Proc Natl Acad Sci. 1997;94(26):14261-6.

37. Guimarães CT, Honeycutt RJ, Sills GR, Sobral BW. Genetic maps of Saccharum officinarum $L$. and Saccharum robustum Brandes \& Jew. Ex grassl. Genet Mol Biol. 1999;22(1):125-32.

38. Al-Janabi SM, Honeycutt RJ, McClelland M, Sobral B. A genetic linkage map of Saccharum spontaneum L.'SES 208'. Genetics. 1993;134(4):1249-60.

39. Zhang J, Nagai C, Yu Q, Pan Y-B, Ayala-Silva T, Schnell RJ, Comstock JC, Arumuganathan AK, Ming R. Genome size variation in three Saccharum species. Euphytica. 2012;185(3):511-9.

40. Zhang J, Arro J, Chen Y, Ming R. Haplotype analysis of sucrose synthase gene family in three Saccharum species. BMC Genomics. 2013;14:314.

41. Zhang Q, Hu W, Zhu F, Wang L, Yu Q, Ming R, Zhang J. Structure, phylogeny, allelic haplotypes and expression of sucrose transporter gene families in Saccharum. BMC Genomics. 2016;17:88.

42. Li P, Ponnala L, Gandotra N, Wang L, Si Y, Tausta SL, Kebrom TH, Provart N, Patel $R$, Myers $C R$, et al. The developmental dynamics of the maize leaf transcriptome. Nat Genet. 2010;42(12):1060-7.

43. Ray M, Moore PH, Zee F, Abbey CA, Ma H, et al. Theor Appl Genet. 2001; 102:892-9.

44. Bankevich A, Nurk S, Antipov D, Gurevich AA, Dvorkin M, Kulikov AS, Lesin VM, Nikolenko SI, Pham S, Prjibelski AD, et al. SPAdes: a new genome assembly algorithm and its applications to single-cell sequencing. J Comput Biol. 2012;19(5):455-77

45. Smit A, Hubley, R, Green P: RepeatMasker Open-4.0. http://www. repeatmasker.org. 2013-2015.

46. Hu B, Jin J, Guo AY, Zhang H, Luo J, Gao G. GSDS 2.0: an upgraded gene feature visualization server. Bioinformatics. 2015:31(8):1296-7.

47. Corpet F. Multiple sequence alignment with hierarchical clustering. Nucleic Acids Res. 1988;16(22):10881-90.

48. Larkin MA, Blackshields G, Brown NP, Chenna R, McGettigan PA, McWilliam $\mathrm{H}$, Valentin F, Wallace IM, Wilm A, Lopez R, et al. Clustal W and Clustal X version 2.0. Bioinformatics. 2007;23(21):2947-8.

49. Tamura K, Dudley J, Nei M, Kumar S. MEGA4: molecular evolutionary genetics analysis (MEGA) software version 4.0. Mol Biol Evol. 2007;24(8): 1596-9.

50. Wang D, Zhang Y, Zhang Z, Zhu J, Yu J. KaKs_Calculator 2.0: a toolkit incorporating gamma-series methods and sliding window strategies. Genomics Proteomics Bioinform. 2010;8(1):77-80. 
51. Bolger AM, Lohse M, Usadel B. Trimmomatic: a flexible trimmer for Illumina sequence data. Bioinformatics. 2014;30(15):2114-20.

52. Trapnell C, Roberts A, Goff L, Pertea G, Kim D, Kelley DR, Pimentel H, Salzberg SL, Rinn JL, Pachter L. Differential gene and transcript expression analysis of RNA-seq experiments with TopHat and cufflinks. Nat Protoc. 2012;7(3):562-78.

53. Yue W, Sun W, Rao RSP, Ye N, Yang Z, Chen M. Non-targeted metabolomics reveals distinct chemical compositions among different grades of Bai Mudan white tea. Food Chem. 2019;277:289-97.

54. Chen L, Huang Y, Xu M, Cheng Z, Zhang D, Zheng J. iTRAQ-based quantitative proteomics analysis of black Rice grain development reveals metabolic pathways associated with anthocyanin biosynthesis. PLoS One. 2016;11(7):e0159238.

55. Borchert N, Dieterich C, Krug K, Schutz W, Jung S, Nordheim A, Sommer RJ, Macek B. Proteogenomics of Pristionchus pacificus reveals distinct proteome structure of nematode models. Genome Res. 2010;20(6):837-46.

\section{Publisher's Note}

Springer Nature remains neutral with regard to jurisdictional claims in published maps and institutional affiliations.

\section{Ready to submit your research? Choose BMC and benefit from:}

- fast, convenient online submission

- thorough peer review by experienced researchers in your field

- rapid publication on acceptance

- support for research data, including large and complex data types

- gold Open Access which fosters wider collaboration and increased citations

- maximum visibility for your research: over $100 \mathrm{M}$ website views per year

At $\mathrm{BMC}$, research is always in progress.

Learn more biomedcentral.com/submissions 